\title{
Transformative Learning and Inclusion in a Global Social Work Course
}

\section{Joan Pittman \\ Deborah Gioia}

\begin{abstract}
As there are many types of global learning experiences for students, understanding best practices is critical in resource allocation and developing competencies. Additionally, diversifying global education is essential in addressing unequal student access and improving cross-cultural competence. This paper describes a short-term international course with graduate students from social work, public health, and nursing. Nine students participated in semi-structured interviews about the impact of the course on their lives. Transformative learning theory emerged as an important pedagogical guide as students described transformations in lifestyle and perspectives that developed through experiential learning. Recommendations for improving learning and increasing cultural and interprofessional learning include having guided group discussions on critical incidents, using a critical reflection process focused on cultural assumptions, and focusing on the psychological, convictional, and behavioral dimensions of learning. Traditionally underrepresented students described barriers related to international study, further emphasizing the importance of encouraging underrepresented students to pursue global opportunities through mentoring, targeted marketing, and making international experiences affordable and logistically feasible. Inclusion of students from different backgrounds in international courses is not only important in promoting social justice, but also enhances cross-cultural skill development and learning.
\end{abstract}

Keywords: Transformative; global education; diversity; inclusion; interprofessional

We work and live in a global world, and therefore it is essential for social workers to understand global social work to be effective practitioners in any community (Healy, 2008). International educational experiences have the potential to broaden and challenge students' worldview, strengthen professional identity, and deepen cultural sensitivity (Bell \& Anscombe, 2013; Dorsett, Clark, \& Phadke, 2017; Gilin \& Young, 2009; Greenfield, Davis, \& Fedor, 2012; Roholt \& Fisher, 2013). Global learning experiences can help students develop skills in all nine of the competencies outlined by the Council on Social Work Education (CSWE, 2015), and can be particularly impactful in demonstrating professional identity and behavior (Competency 1), increasing awareness and appreciation of difference (Competency 2), and understanding "the global interconnections of oppression and human rights violations" (Competency 3, p. 7).

There are many ways to learn about global social work: on-campus courses, localglobal initiatives, service learning, semester study abroad coursework and/or field experiences, and short-term immersion courses (Greenfield et al., 2012; Tarrant, Rubin, \& Stoner, 2013). Short-term international experiences are the largest and fastest growing option because of convenience and affordability and can be effective in achieving learning outcomes (Dorsett et al., 2017; Roholt \& Fisher, 2013; Tarrant et al., 2013). The experience of cultural immersion and being placed in the position of others often results in a deeper

Joan Pittman, PhD, Clinical Associate Professor, and Deborah Gioia, PhD, Associate Professor, University of Maryland Social of Social Work, Baltimore, MD 21201

Copyright (C) 2019 Authors, Vol. 19 No. 2 (Fall 2019), 446-462, DOI: 10.18060/22899

(cc) BY

This work is licensed under a Creative Commons Attribution 4.0 International License. 
level of cultural humility and respect, a critical skill for all social workers (Gilin \& Young, 2009; Roholt \& Fisher, 2013). As Healy (2008) describes, the goals of global social work education should include not only increased awareness of the global context but also professional action in being able to assist families, individuals, and communities from different countries, engage in problem-solving about global social problems, and assess the influence and interaction of regional, national, and international policies.

This article describes a short-term international course with social work, public health, and nursing students in Kerala, India, in 2017. The project adds to the literature on global education by using transformative learning theory (Mezirow, 2000) as a guiding pedagogical framework. In particular, interviews with the students illuminated transformational aspects of the course as well as barriers and advantages of minority graduate student participation in global education.

\section{Transformative Learning Theory}

Global education experiences have the potential to be transformative, and several scholars have examined the use of transformative learning theory in understanding and improving learning in short-term immersion courses (Dorsett et al., 2017; Roholt \& Fisher, 2013; Walters, Charles, \& Bingham, 2017). Transformative learning theory was originally developed through qualitative research methods to understand adult women returning to school for professional development (Mezirow, 1991, 2000). The theory is built on the idea that adult learners have established frames of reference and assumptions, and a primary goal of education is to help adults challenge these assumptions through "disorienting" experiences, critical reflection and dialogue, and action (Alfred, Cherrstrom, Robinson, \& Friday, 2012; Kitchenham, 2008; Mezirow, 1991, 2000). As Merizow (2000) explains:

Transformative learning refers to the process by which we transform our takenfor-granted frames of reference (meaning perspectives, habits of mind, mind-sets) to make them more inclusive, discriminating, open, emotionally capable of change, and reflective so that they may generate beliefs and opinions that will prove more true or justified to guide action. (p. 7)

Mezirow's qualitative research uncovered 10 possible phases of learning: a disorienting dilemma, self-examination with feelings, critical assessment of assumptions, recognition of shared experiences, exploration of new roles/relationships/actions, planning a course of action, acquiring new knowledge and skills, trying out new roles, building competence and confidence in new roles, and reintegration into one's life with new perspectives (Alfred et al., 2012; Kitchenham, 2008; Mezirow, 2000). Much has been written in the transformative learning theory field about types of critical reflection and dialogue, and how to assess and promote these in adult learning (Alfred et al., 2012; Kitchenham, 2008; Mezirow, 2000). Additionally, there have been new developments and critiques of Mezirow's original theory that are important to consider in applying transformative learning theory to global education, including the impact of context, culture, and emotions in perspective transformation (Alfred et al., 2012; Nino, Cuevas, \& Loya, 2011; Walters et al., 2017). Research looking specifically at context suggests that the process of perspective transformation may include three dimensions: psychological 
(changes in understanding of the self), convictional (revision of belief systems), and behavioral (changes in lifestyle; Mezirow, 2000; Nino et al., 2011). Additionally, research suggests that a person's cultural lens, emotions, and relationships may play a more central role in transformative learning than once understood (Alfred et al., 2012; Walters et al., 2017).

Immersive global educational courses may be experienced as disorienting events, potentially starting the "phases" of transformative learning that can lead to psychological, convictional, and behavioral changes. Research on the theory has shown that disorienting experiences must be paired with critical reflection and dialogue to promote the process of cultural learning and perspective transformation. This framework provides guidance for faculty facilitating short-term global courses, highlighting the importance of individual reflection and group dialogue related to critical incidents, and continuing the learning by planning for future action and integration of experiences.

\section{Diversifying Global Education}

International educational experiences are increasingly viewed as an important part of professional development and the number of students participating has more than tripled in the past two decades (Institute of International Education [IIE], 2018). Although statistics for study abroad students from the United States indicate continued improvement in racial and ethnic diversity, the 2015-2016 numbers still highlight significant disparities with $70.8 \%$ of students identified as White, $10.2 \%$ identified as Hispanic or Latino(a), and $6.1 \%$ as Black or African-American (IIE, 2018). These statistics are concerning, considering the increasing research indicating that global educational opportunities improve student academic outcomes and career opportunities (NAFSA: Association of International Educators, 2018). Several studies suggest that employers value study abroad experiences and the intercultural skills that students can develop (Trooboff, Vande Berg, \& Rayman, 2008). Given that international experiences may improve professional competence and expand career opportunities, it seems imperative that these opportunities are accessible to a more diverse student population.

Diversifying global learning opportunities may have benefits for increased learning and cultural sensitivity for minority and non-minority participants as well as the communities visited and the social work profession (Acquaye \& Crewe, 2012; Brux \& Fry, 2010). Just as having more diverse classrooms and workplaces can increase our ability to see the world from different perspectives, having a diverse group of students and faculty participating in global learning provides more opportunities for examining cultural interactions from multiple perspectives. Additionally, traveling to other countries as a diverse, representative group of students from the United States may help host communities have a broader view about American culture (Brux \& Fry, 2010). In particular, in social work education, where our professional mission is to promote social justice, we have an obligation to address inequalities in our schools and communities, and advance inclusivity in all areas of our curriculum (Acquaye \& Crewe, 2012).

Considering the substantial benefits of diversifying global education, it is important to understand and address the barriers to participation for underrepresented students. 
Research in global education has outlined the following categories of barriers that may prevent underrepresented students from participation in global learning: finances, family concerns and attitudes, fear of racism and discrimination, historical patterns in education, disconnect with career goals, and institutional factors such as scheduling difficulties and marketing (Acquaye \& Crewe, 2012; Brux \& Frey, 2010). These barriers were highlighted by traditionally underrepresented participants in this study.

\section{Course Description}

The University of Maryland, Baltimore, School of Social Work (UMB SSW) is a large, public Master of Social Work program located on an urban interprofessional campus. UMB SSW is committed to experiential global education initiatives and has a Center for Global Education Initiatives (CGEI) which supports global interprofessional projects. This shortterm international course was developed with the aim of enhancing cultural sensitivity, interprofessional competence, and international perspectives on health and mental health issues.

UMB SSW has a well-established relationship with the Rajagiri College of Social Sciences, School of Social Work (RCSS SSW) in Kerala, India, and has been offering a winter study abroad course in Kerala since 1997. However, in 2016-2017 the course transitioned to new faculty leadership and was redesigned as an interdisciplinary course with enhanced coursework, assignments, and expectations. CGEI helped to support the course by offsetting costs to students and faculty through a grant, assisting with selection of students, and providing resources and education to students about international travel. Since 2014 there have been over 36 international trips sponsored by CGEI to a wide array of global sites, yielding numerous presentations and publications.

Thirty-four students applied to participate in the international course and eighteen were selected based on academic standing, references, personal statement and essay, and an interview. CGEI has established questions and structured procedures for students applying for international experiences. Student applications included a personal statement and two essays that addressed their interest in the program, fit with their professional goals, and interest and experience in working interprofessionally. Based on all components of the application, each student was rated in categories of interest, experience, professional goals, and quality of references by a member of the CGEI staff and one of the faculty leading the trip. Those ratings along with comments from the interview were compiled and reviewed by the faculty and CGEI staff at a group meeting where applicants were ranked and selected. All of the 18 students chosen were in master's programs at UMB; 3 students were from the Nursing program, one was in a dual degree Public Health/Social Work program, and 14 were in the Social Work program. All of the students identified as women.

\section{Course Content and Structure}

This three credit master's level course titled, Interprofessional Explorations of Aging, Health and Mental Health in a Global Context, consisted of 3 pre-travel classes in the Fall semester, two weeks in India over the Winter term (immersion), and one debriefing class

and a campus presentation in the spring semester (post-travel). Students selected for the 
course were given a detailed syllabus describing learning objectives, dates of classes, readings, assignments, and expectations. A core component of this course was participation in an international conference on Healthy Aging and Mental Health at RCSS in Kerala, India during the first week of travel. The course was led by two social work faculty members with experience and interest in global education and interprofessional practice.

Pre-travel. The goals of the pre-travel phase of the course were to form relationships, learn about different professions, learn about the history and culture of India, explore issues around aging in the United Stated (US) and India, and discuss logistics of the travel portion of the course. We accomplished these goals through small group activities, guest lectures, readings, and assignments. Students were placed in three groups of six students that were tasked with completing a research poster on an aging issue in India and the US. This assignment was instrumental in meeting the goals of forming relationships, learning about different disciplines, learning about the culture in India, and exploring aging issues in the US and India. The research posters were presented at the conference in India, providing an opportunity to engage with students and faculty from India and around the world. Guest lecturers who were from Kerala, former students who had participated in the course, and experts on Indian culture were instrumental in facilitating learning about culture and global perspectives. An essential component of the success of the pre-travel classes was having the support from CGEI. Most students in the course had never been on an international education trip before, so having the Center's assistance with questions about Visas, immunizations, and safety concerns was essential.

Immersion experience. The in-country immersion portion of the course took place during the two week winter break. The first part of the in-country experience involved participation in the Dyuti 2017 International Conference on Healthy Aging and Mental Health at RCSS in Kerala, India. Students in the course attended conference presentations on aging and mental health topics, participated in social and cultural events, and formed relationships with students and faculty from India and other countries. The Dyuti International Conference is unique in that the Masters of Social Work students from RCSS plan and facilitate the conference activities and logistics. Thus, students from UMB and RCSS SSW interacted frequently in both formal and informal ways, and this seemed to be one of the highlights of the program. For example, MSW students from RCSS created an interactive display of information about aging issues in Kerala and UMB students were able to engage with students and discuss the information presented. Students interacted informally with students and faculty from India and other countries during daily tea breaks and lunches at the conference. UMB students also had their research posters displayed and were able to engage with conference participants about their own projects. In addition to conference events, the group visited health and mental health agencies, cultural sites, workplaces, and a family's home.

During the conference and while traveling around Kerala, students were required to write reflections in a journal, and take pictures of scenes that represented the course learning objectives of increasing cultural competence, interprofessional learning, and knowledge about health and mental health issues in India. Additionally, faculty members led small and large group discussions about critical incidents that occurred on the trip, cultural issues, and health and mental health topics. 
Post-Travel. Upon returning from the travel portion of the course, students were asked to review and reflect on their journal entries and photographs relevant to the key learning objectives, and attend the post-travel debriefing class to share ideas about learning themes from the course. For grading purposes, students were required to submit one journal entry and one photograph with a caption that captured important learning for the student. At the post-travel debriefing class, students shared themes, photographs, and journal entries, and worked to synthesize these into four common areas of learning: mental health and spirituality, cross-cultural relationships, women's roles in the workplace, and health and mental health. Students selected journal excerpts and photographs to showcase these themes at a campus event which included a gallery show featuring captioned photographs, research posters, and a brief presentation. Choosing a caption for their photograph, a process derived from the photovoice method (Wang \& Burris, 1997), was useful in enhancing the critical reflection process of the course. Gaining funding and administrative support for global education can be challenging, thus sharing the positive impact of this course with deans and administrators, community members, and other students was a critical step in the process. Additionally, having an end goal of sharing back to the larger community helped students synthesize and communicate what was valuable to them about the course, which seemed beneficial in the learning process.

\section{Method}

Participation in a post-course qualitative interview was voluntary. After grades were submitted for the course, an email was sent to all students asking for participation in a short open-ended qualitative interview about their experiences in the course. Half of the students $(n=9)$ agreed to participate in the interviews. Although demographic information was not collected as part of GCEI's selection process, through exercises and conversations in the course the authors became aware of students' ethnic and racial identification, age, and experience. Forty percent of the students in the course identified as Caucasian, while the remaining $60 \%$ of students identified as a non-Caucasian race/ethnicity or mixed race/ethnicity which was the same percentage as those interviewed. Four of the students interviewed identified as Caucasian, three as Hispanic, and two as African American. Most of the students were in their $20 \mathrm{~s}(\mathrm{n}=7)$; one student was 34 , and one was 64 . Only one student out of 9 had been on an international educational trip before this course.

An interview guide (See Table 1) was created by the authors; questions were framed to be descriptive and evaluative of student experiences on the trip. Specific questions about cultural competence, interprofessional education, and barriers to participation were explored as these concepts were present in the literature and were learning objectives for the course. This paper highlights themes around transformative, cultural, and interprofessional learning which came up in response to many of the questions. Additionally, the experiences of traditionally underrepresented students are highlighted because of the critical need to diversify global education. The experiences of barriers and benefits of having a diverse group of students participate in this course was notable. 
Table 1. Interview Guide Questions

\begin{tabular}{|l|}
\hline Background/demographics: \\
- Age \\
- Advanced standing or not/ Year in the program \\
- Have you been on other international educational trips? If yes how many? \\
Overall experience: \\
- What did you get out of (learn from) this experience? \\
- What did you learn that you think may help you in your profession? \\
- Do you feel this course increased your cultural competence? \\
- Is there an example from the course of how this improved? \\
- $\quad$ phat did you learn about the roles and responsibilities of social work, nursing and/or \\
- Do you think this IPE experience will help your career? Explain \\
\hline Barriers $\quad$ What were the barriers to your participation in this global course? \\
- Were there health/mental health/financial/other concerns that could have preventing \\
Wrap up reflection question \\
- Was there an important (specific) event or experience that facilitated your learning? \\
- Looking back now, do you think taking this course was important in your professional \\
career? How do you know this? What has happened that lets you know this was a good \\
decision?
\end{tabular}

A UMB IRB application was submitted for study approval, and the application was reviewed. However, the determination was that the study was low risk and did not require registration in the system as a formal study with oversight from the IRB committee.

In an effort to increase participation, faculty sent several emails to students inviting them to participate in interviews. On reflection, the time chosen for the interviews was at the end of the academic year and did not favor participation of all the students, especially since many students were graduating. However, it was necessary to wait until the grades were submitted before conducting the interviews, in order to decrease the risk of our dual relationships with the interviewees who were students of the interviewers. Oral consent was given by the students who agreed to an interview and this was captured on the recording. Interviews lasted roughly 15-20 minutes and all the interviews were digitally recorded and transcribed verbatim by the authors. In an effort to increase participation, students were given the option to participate by phone if they could not come in person. Four of the interviews were conducted by phone and five were in person. No compensation was provided to the respondents. 


\section{Data Analysis}

Template analysis was used to develop an a priori set of codes that reflected the study aims (Brooks \& King, 2012). Although a formal codebook was not used, the interviewers derived some agreed-upon codes, taken mainly from the interview guide to use in the coding. Serendipitous comments were also weighed as to their relevance (Padgett, 2016). Due to the small number of interviews, no qualitative data software was used. Each student interview was coded twice by hand, once by each interviewer, and then compared.

A basic qualitative data analysis method was used (Miles, Huberman, \& Saldana, 2013) to aggregate the answers to the interview guide questions and compare and contrast the student responses during the second cycle of coding. A modified form of Consensual Qualitative Research (CQR) (Hill, 2012), characterized by small samples and open-ended questions, was used to understand the findings and to surface themes for discussion by the authors. In the CQR approach, a dialogue is employed by the research team to understand the data and make decisions about which quotes have density to put forward as themes.

\section{Findings}

The interview data revealed four primary themes: transformative learning, cultural learning, interprofessional learning, and barriers for minority students. Students were asked directly about cultural competence and interprofessional learning since these were course objectives, but as the findings show, when asked more general questions about what they gained from the experience nearly all students shared that cultural and interprofessional learning were an important part of the experience. Students were not asked specifically about transformative learning, rather it arose spontaneously from students' responses to questions about their overall experience. A question about barriers to participation was asked of all students; however there was a clear theme that students of color had barriers related to being a minority student that non-minority students did not report.

\section{Transformative Learning}

In response to questions in the interview guide, students described their experiences as transformative, causing adjustment of previously held assumptions and priorities and major life changes. Five of the nine students interviewed gave specific examples of ways that this course changed their beliefs and behaviors both personally and professionally. These students described how the immersive experience of the international course resulted in changes in understanding of self (psychological), revision of belief systems (convictional), and lifestyle changes (behavioral; Mezirow, 2000; Nino et al., 2011).

One example was a student who described how the course caused her to reevaluate her beliefs and behaviors around how to live her life and what was important, leading to lifestyles changes such as "turning off notifications on my devices" and "being present." She further explained:

We struggle as nurses with self-care because we take so much energy of ourselves into the care of other people. And I'm sure that that goes the same way for social work as well. And like nursing is so fraught with burnout and anxiety and all of 
these really negative things because we lack the capacity or the will to give of ourselves to ourselves. So as I've come back I've gotten really involved (in) the self-care group on the unit level and the hospital level.

Another student reported increased self-confidence and self-awareness, which could be categorized as psychological and convictional domains of perspective transformation, and changes in lifestyle (behavioral domain) as a result of participation in the course.

When I came back home...just everything changed... I decided to quit my job and I just learned that I have to really do what I want to do, and just live life [more meaningfully], that's just how it felt. I also learned that, because I never thought that this trip would ever happen, [and then] it did. Now I'm more convinced that whatever you want, if you try hard enough you can have it.

Another student echoed the increased self-confidence and perspective transformation resulting from the course.

This is going to be something I'll take with me for the rest of my life...I guess the courage... just like even though I knew nobody, and I was not very familiar with social work. I'd never been to Asia. Despite all of those things having the courage to just like go for it, and it worked out so well, that yeah, I will take with me like a building block for more opportunities and seeking out more opportunities in the future.

The experience solidified one student's professional identity which could be described as psychological and convictional perspective changes, and allowed her to explore different areas of social work.

I didn't feel like a social worker until I went to the conference at Rajagiri College.

Because I felt like a part of a bigger thing ... After that (the course) I have been searching for careers in nursing homes. Its opened an entire door of interest.

Critical reflection and dialogue were encouraged through daily journaling and facilitated group discussions. Although most students did not specifically describe how journal reflections and group dialogues assisted in the learning process, students did describe critical incidents that occurred on the trip and these were incidents that were discussed in large and small groups and processed in their journals. In hindsight it would have been helpful to ask specifically about the impact of journaling and group dialogue and explore what was most helpful to students in facilitating critical reflection and learning. One student did describe the importance of guided group discussions in improving learning and integrating experiences and knowledge.

One of my most favorite moments was the conversations that we had on the boat houses. I don't want to speak for everyone else but it seemed that everyone had really rich conversation, and we had prompts [guiding questions] too. If there's not guidance, it's not like everyone is just going to organically get together and start talking. 


\section{Cultural Learning}

All of the students interviewed except for one felt that the course increased their cultural competence. Students described increased knowledge of Indian culture, increased confidence in interacting with clients and families from different cultures, and increased cultural humility. Gaining experience about cross-cultural communication seemed particularly impactful for several students. One example of this was when some students felt that the students from India were being rude or pushy, but after debriefing discussions and forming relationships, they began to understand the communication differently.

I think there was this perception that the students (in India) were being pushy or a little bit aggressive in terms of what they wanted us to do. And then I think through our two weeks there we realized that they are not trying to be pushy or force these activities on us, it's really that the end goal for them was for us to have a really great experience.

Another student described cultural learning that occurred as related to the diversity of our US student group interacting with the Indian student group:

As far as competency, we found out how they [Indian social work students] act toward each other, things that you can't do there, how they dress... We were really serious about learning their language and having conversations with people...They were surprised, because, number one, they did not see too many African Americans, Black people that travelled there.... Culturally it was very important and I loved it.

Spending a day in the home village of an Indian family was also a highlighted experience in student journals that seemed to increase cultural humility and understanding of norms and customs.

\section{Interprofessional Learning}

In response to the interview guide questions on interprofessional learning, seven of the students felt that interprofessional learning was a very important part of their experience and would improve their professional skills. One student did not feel that she learned new information or skills about the other professions because she had already participated in several in-depth interprofessional projects. Another student shared that having more preparation and discussion about interprofessional concepts before visiting agencies while in India could have strengthened the learning.

The seven students with positive comments about interprofessional learning described learning about different professional roles, values, and styles of working. These students felt that visits to health and mental health facilities in India were enhanced by having students from different professions present because questions were asked from multiple perspectives, and discussions after the visits included new multidisciplinary knowledge that provided a richer understanding of the issues. As one social work student explained:

It made me appreciate the more medical side [of the social issue], and it made me see things differently than if they (nursing students) hadn't been there. 
A nursing student explained that learning about the roles and education of social workers changed her professional behavior when she returned to working in a hospital:

Now since coming back I have had so many more ideas of how we can better utilize her (hospital social worker) ... not just using her (hospital social worker) to get in touch with resources, but also using her as a resource.

\section{Barriers for Minority Students}

Based on the literature regarding underrepresentation of students of color in international education, a question was included that asked about barriers to participation in this course. Four of the interviewed students identified as Caucasian/White, three as Hispanic, and two as African American. The four students that identified as Caucasian described barriers of financial and work concerns, being drained from travel upon returning home, and difficulties with the process of obtaining a visa for India. One of the persons of color was accidentally not asked about barriers and one described barriers related to child care, but no specific cultural issues.

Three students that identified as African American or Hispanic described barriers connected to their race/culture or family background. One student stated that she was not going to apply, but ended up submitting her application after encouragement from a former supervisor. When asked why she might not have applied, she responded,

I don't know, I feel like, in my past experiences I haven't really seen study abroad opportunities offered so much to African-American students. And I don't know if I sort of internalized that, and felt that because I am African-American, maybe I won't be selected for this opportunity.

One of the students of color talked about financial barriers and other values around obtaining vaccinations for travel.

A lot of times in my culture they don't take too many medicines or too many shots and they would use herbal remedies or teas. So getting the shots [vaccines] and the other things that were recommended for the trip - I was struggling with that too. So I don't really like doing this, but I don't want to get sick. So I had to kind of go against some things because I wanted to be okay on the trip.

Another student of color talked about how participation in international educational trips was not normative in her family.

Just me not thinking I was worthy enough to go on this trip. That was more of what it was. Because I'm the first in my family to travel that far. You know it started off as kind of like a fantasy conversation and then it happened! I told my grandparents and they didn't understand [and asked] What are you going to India for? Why? By yourself? Like they really didn't get it. My parents were all for it. They were super supportive and they were really excited for it. But it's just one of those things, they themselves wouldn't go to India. 


\section{Limitations}

As with any study, the findings must be considered in light of the limitations. The primary purpose of this exploratory study was to understand the students' experiences on this international educational trip, and to identify areas that could be strengthened for future courses. Although only a short period of time had passed when we conducted the interviews, it is possible that the study participants may have suffered from recollection bias, as well as the desire to please the interviewers, who were also the course instructors. These student experiences were tied to one class, from one graduate institution, potentially narrowing the applicability to other academic institutions and courses.

As noted, only half of the students from the course participated in the interviews. The end of semester timing may have been a factor in the response rate. Efforts were made to increase participation by sending multiple emails and offering students the option to participate by phone or in person. The interviews that were conducted by phone did not adequately give the interviewers a chance to observe reactions to questions and to probe more deeply. Although students did speak freely about their experiences and were provided a variety of opportunities to provide positive and negative feedback, restrictions in critical comments may have been a function of the student/faculty power dynamic. Both faculty were in social work and there were only a few nursing and public health students in the course and in the interviews, therefore, these findings may be skewed toward the social work student experience.

\section{Discussion}

\section{Transformative Learning}

Although these nine interviews represent only half of the students from one course, the findings add to the growing literature that short-term international courses can be transformative learning opportunities (Bell \& Anscombe, 2013; Dorsett et al., 2017; Gilin \& Young, 2009; Roholt \& Fisher, 2013; Walters et al., 2017). For many students, participating in a longer-term global immersion experience is not logically or financially possible, thus short-term immersion courses offer an obtainable option that may have lasting effects. Using the 10 phases of transformative learning (i.e., disorienting dilemma, self-examination, critical reflection, planning for and integration of new roles and actions) as a guide to structure global courses may be helpful in promoting and extending the lessons learned (Alfred et al., 2012; Kitchenham, 2008).

Immersive international courses have the benefit of students and faculty being placed in the position of other and learning new skills and ideas experientially (Dorsett et al., 2017; Gilin \& Young, 2009; Roholt \& Fisher, 2013). These immersive experiences can create critical incidents or "disorienting dilemmas," the first phase of transformative learning. The main disorienting event for students in this course was first time travel to India. Within the travel experience, other "culture shocks" arose in what they observed and experienced. Faculty cannot always plan for what will be a disorienting event, or when these events will occur, but the goal of faculty facilitation is to stay alert for these opportunities, ready to help students reflect on their experiences. 
According to transformative learning theory, the next phases of learning include critical reflection and dialogue around assumptions, beliefs, emotions, relationships, and roles (Alfred et al., 2012; Kitchenham, 2008; Mezirow, 2000). Perhaps because students were not asked to elaborate on how they learned but instead what they learned, only one student interviewed highlighted the importance of guided group dialogues. However, faculty observations, anecdotal student comments, and prior research support the idea that group facilitated discussions are critical for integrating experiences and challenging assumptions (Nino et al., 2011; Roholt \& Fisher, 2013). It is often difficult, especially with large groups of students and intense travel schedules, to allow ample time for these periods of discussion and reflection. Transformative learning theory outlines a critical reflection process as including identifying assumptions, challenging these assumptions based on experiences, integrating information to form new assumptions, and taking action based on the new integrated material (Mezirow, 2000; Roholt \& Fisher, 2013). An example of how this occurred in this course was when we had a large group debriefing about how students were interpreting non-verbal communication from students from other countries as "being rude." After identifying and challenging the assumptions and integrating the new information, students were able to engage with students from other cultures in a different way. This example also highlights how the transformative learning process can improve intercultural skills and cultural competence. Critical reflection processes outlined in transformative learning theory can contribute to increased cultural sensitivity by helping students examine biases, stereotypes, and understand the meaning that people give to events (Askeland \& Fook, 2009). Further research and practice on the use of transformative learning theory to improve cultural competence may be useful since they appeared to be interlocking concepts.

Student interviews touched on the different domains of perspective transformation (psychological, convictional, and behavioral), suggesting that global courses may improve learning outcomes if experiences and discussion questions are targeted to address these different elements. Since these themes arose from the student data, we did not ask specific questions about the three domains of transformative learning. It would be helpful in future studies to gather more information on these domains including what facilitates changes in these areas. Additionally, educators could extend learning by including course elements on the later transformative learning phases such as exploring new roles, beliefs, or behaviors that students would like to implement after the course and integrating learning and new perspectives. Students in this course reported their intent to make significant personal and professional changes as a result of the experience. Having post-travel discussions and a campus presentation appeared to help students integrate the experiences and new beliefs; however, faculty could have facilitated more targeted discussions and goal-setting around changes that students planned to make upon return.

Improved understanding and appreciation of different professions was an important learning outcome of this course, and transformative learning theory concepts may be helpful in expanding learning in this area. Students shared how critical dialogue and reflection was enhanced by having different professional perspectives present, improving individual student learning and the potential for students to engage in interprofessional practice when returning to their professional roles. Having a more balanced representation 
of different professions and including more post-trip elements on integration of new ideas and roles could enhance interprofessional learning.

\section{Diversifying Global Courses}

Student interviews post-travel provided further support to the growing literature on barriers for students of color and the need to increase access to international experiences (Acquaye \& Crewe, 2012; Brux \& Fry, 2010; IIE, 2018). Students of color, those who have come from low socioeconomic backgrounds, and students who have not had exposure to global experiences often do not apply for these programs, because they have not seen others like them apply, and are not convinced that they would be comfortable on these trips. Student voices from this study further emphasize the importance of encouraging underrepresented students to pursue global opportunities through mentoring, targeted marketing, and making international experiences affordable and logistically feasible.

Learning was enhanced in this course because of the diverse cultures and experiences of the students participating. Women of color had different experiences of being stared at, having questions about their hair, and concerns about being discriminated against. Being able to discuss these cross-cultural experiences as a group enriched the learning experience and likely improved students' cultural sensitivity.

One of the possible reasons this course attracted a diverse group of students, most of whom had not previously participated in an international education experience, may have been because the course cost was reduced with grant support given by the GCEI. One of the students interviewed shared how she was pleasantly surprised that she was not the only person of color in the course, and that made her feel more comfortable with her decision to participate. Ensuring that marketing materials, student panels, and faculty teaching the courses are diverse may help students of color feel that they can apply and participate in these experiences. Other suggestions from the literature on attracting diverse students include creating spaces to talk about safety and discrimination concerns, partnering with diverse student groups, and developing curricula that is responsive and inclusive of diverse points of view (Acquaye \& Crewe, 2012; Bruce, 2015). Diversifying international opportunities supports the social work value of promoting social justice and enhances the experience for all participants, creating more opportunities for cross- cultural dialogues and deeper critical thinking.

\section{Future Directions}

Transformative learning theory, specifically the phases of learning, domains of perspective transformation, and types of reflection and dialogue, could be used to improve learning outcomes in short-term global courses by designing courses based on these concepts. Future research could include a richer exploration of transformative learning theory concepts, and their connection to cultural and interprofessional learning. Researchers could also use student interviews and a content analysis of journals. Analysis of journal entries, coupled with retrospective interviews, would build on this qualitative study by triangulating different data sources, and serve to increase knowledge about transformative learning in graduate education. 
Although many students reported psychological, convictional, and behavioral changes when interviewed a few months after the course, it is unknown if these changes were lasting or if they improved their professional competence. A second data collection point would help researchers understand the durability of these changes. Additionally, as faculty teaching this course for the first time, there were many elements of the course that could be improved to promote learning including having more frequent group dialogues, having some groups facilitated by members of the host country (Roholt \& Fisher, 2013), including faculty from other disciplines, and structuring journal prompts and discussions around transformative learning concepts.

Despite the exploratory nature of these qualitative interviews, and the fact that the data may give rise to multiple interpretations, these findings have generated some new ways of thinking about global coursework. In particular, the value of using transformative learning theory will improve global courses by tuning into disorienting events, bolstering critical reflection and dialogue, and providing opportunities for integration of changes into personal and professional roles. Student and faculty experiences validated prior research about the barriers and benefits of diversifying global education, and this course provides new insights into the importance of making global courses affordable, feasible, attractive, and meaningful for underrepresented students.

\section{References}

Acquaye, L., \& Crewe, S. (2012). International programs: Advancing human rights and social justice for African American students. Journal of Social Work Education, 48(4), 763-784. doi: https://doi.org/10.5175/jswe.2012.201100130

Alfred, M., Cherrstrom, C., Robinson, P., \& Friday, A. (2012). Transformative learning theory. In J. B. Irby (Ed.), The handbook of educational theories (pp. 133-145). Charlotte, N.C: Information Age Pub.

Askeland, G., \& Fook, J. (2009). Critical reflection in social work. European Journal of Social Work, 12, 287-292. doi: https://doi.org/10.1080/13691450903100851

Bell, K., \& Anscombe, A. (2013). International field experiences in social work: Outcomes of a short-term study abroad programme to India. Social Work Education, 32(8), 1032-1047. doi: https://doi.org/10.1080/02615479.2012.730143

Brooks, J., \& King, N. (2012, April). Qualitative psychology in the real world: The utility of template analysis. Paper presented at the British Psychological Society Annual Conference, London. Retrieved from http://eprints.hud.ac.uk/id/eprint/13656/1/Brooks King_QMiP 2012 Final.pdf

Bruce, A. (2015, May 18). 7 ways to attract diverse students to study abroad. Chronicle of Higher Education. Retrieved from https:/www.chronicle.com/article/7-Ways-toAttract-Diverse/230149

Brux, J., \& Fry, B. (2010). Multicultural students in study abroad: Their interests, their issues, and their constraints. Journal of Studies in International Education, 14(5), 508-527. doi: https://doi.org/10.1177/1028315309342486 
Council on Social Work Education [CSWE]. (2015). Educational policy and accreditation standards. Retrieved from https://www.cswe.org/getattachment/Accreditation/Accreditation-Process/2015EPAS/2015EPAS_Web_FINAL.pdf.aspx

Dorsett, P., Clark, J., \& Phadke, S. (2017). India Gateway Program: Transformational learning opportunities in an international context. International Social Work, 60(4), 883-896. doi: https://doi.org/10.1177/0020872815580041

Gilin, B., \& Young, T. (2009). Educational benefits of international experiential learning in an MSW program. International Social Work, 1, 36-47. doi: https://doi.org/10.1177/0020872808093347

Greenfield, E. A., Davis, R. T., \& Fedor, J. P. (2012). The effect of international social work education: Study abroad versus on-campus courses. Journal of Social Work Education, 48(4), 739-761. doi: https://doi.org/10.5175/jswe.2012.201100147

Healy, L. (2008). International social work: Professional action in an interdependent world. Oxford, UK: Oxford University Press.

Hill, C. E. (2012). Consensual qualitative research: A practical resource for investigating social science phenomenon. Washington D.C.: APA.

Institute of International Education [IIE]. (2018). Open doors 2018 fast facts. Retrieved from https://www.iie.org/-/media/Files/Corporate/Open-Doors/Fast-Facts/Fast-Facts2018.ashx?la=en\&hash=E87E077CE69F84A65A9AA0B0960C2691E922835A

Kitchenham, A. (2008). The evolution of John Mezirow's transformative learning theory. Journal of Transformative Education, 6(2), 104-123. doi: https://doi.org/10.1177/1541344608322678

Mezirow, J. (1991). Transformative dimensions of adult learning. San Francisco: JosseyBass.

Mezirow, J. (2000). Learning as transformation: Critical perspectives on a theory in progress. San Francisco: Jossey-Bass.

Miles, M. B., Huberman, A. M., \& Saldana, J. (2013). Qualitative data analysis: A methods sourcebook (3rd ed.). Thousand Oaks, CA: Sage.

NAFSA: Association of International Educators. (2018). Independent research measuring the impact of study abroad. Retrieved from http://www.nafsa.org/Policy and Advocacy/Policy_Resources/Policy Trends and Data/Independent_Research_Measuring_the_Impact_of_Study_Abroad/

Nino, M., Cuevas, M., \& Loya, M. (2011). Transformational effects of service-learning in a university developed community-based agency. Advances in Social Work, 12, $33-48$.

Padgett, D. K. (2016). Qualitative methods in social work research (3rd ed.). Thousand Oaks, CA: Sage. 
Roholt, R., \& Fisher, C. (2013). Expect the unexpected: International short-term study courses pedagogies and practices. Journal of Social Work Education, 49, 48-65. doi: https://doi.org/10.1080/10437797.2013.755416

Tarrant, M. A., Rubin, D. L., \& Stoner, L. (2013). The added value of study abroad: Fostering a global citizenry. Journal of Studies in International Education, 18(2), 141-161. doi: https://doi.org/10.1177/1028315313497589

Trooboff, S., Vande Berg, M., \& Rayman, J. (2008). Employer attitudes toward study abroad. Frontiers: The Interdisciplinary Journal of Study Abroad, 15, 17-33.

Walters, C., Charles, J., \& Bingham, S. (2017). Impact of short-term study abroad experiences on transformative learning: A comparison of programs at 6 weeks. Journal of Transformative Education, 15(2), 103-121. doi: https://doi.org/10.1177/1541344616670034

Wang, C., \& Burris M. A. (1997). Photovoice: Concept, methodology and use for participatory needs assessment. Health, Education \& Behavior, 24(3), 369-387. doi: https://doi.org/10.1177/109019819702400309

Author note: Address correspondence to: Dr. Joan Pittman, Clinical Associate Professor, University of Maryland School of Social Work, 525 W. Redwood St., Baltimore, MD 21201. E-mail:.jpittman@ssw.umaryland.edu. 